\title{
The role of hybrid positron computed emission
} tomography in evaluation of metastatic activity in breast cancer

\section{Uloga hibridnog sistema pozitronske emisione kompjuterizirane tomografije u procjeni metastatske aktivnosti kod karcinoma dojke}

\author{
Omar Bataine1, Sandra Vegar-Zubović2, Fuad Julardžija1, Jasmina Bajrović2, Nusret Salkica3 \\ 1Faculty of Health Studies, University of Sarajevo, Bosnia and Herzegovina \\ 2Radiology clinic, Clinical center of Sarajevo University, Bosnia and Herzegovina \\ 3Clinic for Nuclear Medicine and Endocrinology, Clinical center of Sarajevo, University, Bosnia and Herzegovina \\ Corresponding author: Omar Bataine, Fakultet zdravstvenih studija Univerziteta u Sarajevu, Stjepana Tomića 1, 71000 Sarajevo, Email: \\ omar_bataine@hotmail.com \\ Received:11.07.2020. \\ Accepted:15.10.2020 \\ DOI: https://doi.org/10.48026/isnn.26373297.2020.11.1.6
}

\begin{abstract}
Introduction: Among the female population, breast cancer is the most commonly diagnosed cancer in the world, and nearly half of women population with breast cancer develop metastatic disease during their lifetime. Breast cancer most often metastazises to the lungs, liver, bones, brain and lymph nodes. 18F-FDG PET/CT can detect metastases that are not visible in other imaging modalities, and with the newly discovered lesions, decision about adequate treatment option can be evaluated.

Material and methods: The examination was conducted as a retrospective descriptive study in May and June of 2019 at the Clinic for Nuclear Medicine and Endocrinology of the University Clinical Center in Sarajevo. It included 100 female patients with the age structure of 33-79 years. The patient's reference diagnosis is breast cancer, with a suspected finding of metastatic activity. A comparison of the sensitivity and specificity of the breast imaging between PET/CT, CT and bone scintigraphy was performed.

Results: PET/CT revealed significantly more positive findings on metastatic activity than other diagnostic imaging modalities, with Mann-Whitney test value of $p=0.01014$. In the diagnosis of lungs and liver lesions, PET/CT sensitivity and specificity are $92.59 \%$ and $85.37 \%$, respectively, while the statistical parameters for CT are $77.78 \%$ for sensitivity and $90.24 \%$ for specificity. The PET/CT sensitivity and specificity for bone lesions are $93.55 \%$ and $88.89 \%$, respectively, compared to $78.57 \%$ and $100 \%$ for bone scintigraphy.

Conclusion: Hybrid imaging technique, which integrates PET and CT imaging methods, has considerable advantages over other diagnostic methods in the detection of distant metastases, and based on obtained results, PET/CT may be method of choice in evaluation of metastatic activity in breast cancer.
\end{abstract}

Keywords: PET, CT, PET/CT, breast cancer, metastatic breast cancer, 18F-FDG, bone scintigraphy

Apstrakt

Uvod: Među ženskom populacijom karcinom dojke je najčešće dijagnosticirani karcinom na svijetu, a skoro polovina žena oboljelih od karcinoma dojke razvije tokom svog života i metastatsku bolest. Karcinom dojke najčešće metastazira u pluća, jetru, kosti, mozak i limfne čvorove. PET/CT sa 18FFDG može detektirati metastaze koje nisu vidljive na drugim modalitetima i uz pomoć tih pronalazaka se može mijenjati odluka za opciju tretmana.

Materijal i metode: Istraživanje je sprovedeno kao retrospektivno deskriptivna studija u mjesecu maju i junu 2019. godine na Klinici za nuklearnu medicinu i endokrinologiju Univerzitetskog kliničkog centra u Sarajevu. Uključivala je 100 pacijenata ženske populacije dobne strukture između 
33-79 godina. Uputna dijagnoza pacijentica je karcinom dojke, sa suspektnim nalazom na metastatsku aktivnost. Izvršena je komparacija senzitivnosti i specifičnosti imidžinga dojke između PET/CT, CT i scintigrafije kostiju.

Rezultati: PET/CT je otkrio statistički značajno više pozitivnih nalaza na metastatsku aktivnost u odnosu na druge dijagnostičke modalitete, uz Mann-Whitneyev test vrijednosti $\mathrm{p}=0,01014$. U dijagnostici lezija na plućima i jetri, PET/CT je pokazao senzitivnost i specifičnost od $92,59 \%$ i $85,37 \%$, dok statistički parametri za CT iznoste $77,78 \%$ za senzitivnost i $90,24 \%$ za specifičnost. Senzitivnost i specifičnost PET/CT za lezije na skeletu iznose 93,55\% i 88,89\% respektivno, u odnosu na 78,57\% i 100\% za scintigrafiju kostiju.

Zaključak: Hibridna tomografska tehnika snimanja koja objedinjuje slikovne metode PET i CT, ima znatne prednosti nad drugim dijagnostičkim metodama u detekciji udaljenih metastaza, te posmatrajući dobivene rezultate, PET/CT može biti metoda izbora u procjeni metastatske aktivnosti kod karcinoma dojke.

Ključne riječi: PET, CT, PET/CT, karcinom dojke, metastatski karcinom dojke, 18F-FDG, scintigrafija kostiju

\section{Uvod}

$\mathrm{P}$ ET/CT je hibridna, neinvazivna imidžing tehnika gdje PET pruža biohemijske i funkcionalne informacije o posmatranom tkivu dok CT pruža informacije o morfološkoj i anatomskoj strukturi (1).

Slika koja se dobije CT modalitetom se formira dejstvom x-zraka, dok se PET slika dobije detektiranjem zračenja koju uzrokuju radioobilježeni traseri koji su prethodno intravenozno injicirani u pacijenta (2). Benefiti $\mathrm{PET} / \mathrm{CT}$ procedure u odnosu na PET i CT procedure pojedinačno su dokumentovane $\mathrm{u}$ više od 12000 objavljenih publikacija širom svijeta (3).

Prema službenim vodičima za karcinom dojke, 18F-FDG PET/CT nije indiciran kod žena sa ranim stadijem karcinoma dajke (stadij I i II), pa čak ni kod onih sa operabilnim trećim stadijem; međutim smatra se optimalnim za žene sa dvosmislenim ili sumnjivim otkrićima na CT i MRI nalazima te kod žena sa lokalno uznapredovalim karcinomom dojke, posebno uznapredovale invazije kod aksilarnih čvorova, jer postoji rizik od ranih udaljenih metastaza koji je dovoljno velik da se opravdava sistemski stejdžing kao dio početne procjene (4).

U takvim okolnostima PET/CT sa 18F-FDG može detektirati metastaze koje nisu vidljive na drugim modalitetima i uz pomoć tih pronalazaka se može mijenjati odluka za tretmansku opciju. Sa takvim mogućnostima PET/CT se logično nameće kao jedna od metoda izbora za procjenu metastatske aktivnosti kod karcinoma dojke, ali još uvijek nije dio rutinske pretrage za stejdžing i procjenu metastatske aktivnosti karcinoma dojke (5).

PET je esencijalno kvantitativna medicinska imidžing metoda koja mjeri distribuciju i uptake radiotrasera kvantitativno in vivo. Ona samim tim pruža kvantitativno mjerenje osnovne biologije, kao što je metabolizam, gustoća receptora, aktivnosti ili informacije o transporteru u ovisnosti od radiotrasera koji se koristi. FDG je široko rasprostranjen i koristi se u kliničkoj upotrebi te pruža kvantitatvni indeks metabolizma glukoze. Visoki nivoi se povezuju sa malignitetom i samim tim se PET koristi za stejdžing, prognozu i monitoring. Mjerenje se očitava u standardiziranim vrijednostima nakupljanja (SUV), gdje se vrijednosti do 2,5 na skali posmatraju metabolički normalnim, nemalignim tkivom (6).

Stav mnogih autora jeste da je PET/CT u prednosti u odnosu na PET i CT odvojeno zbog združene prirode prikaza funkcionalnosti i anatomije, zbog bolje lokalizacije patoloških područja, kraćeg vremena akvizicije, te prevazilaženja limitirane specifičnosti PET skenera (7-8). Problemi u procjeni metastatske aktivnosti se ogledaju u relativno niskoj incidenci metastaza u najranijem stadiju karcinoma, te postojanju mogućnosti za lažno pozitivnim nalazima. Cilj rada je predstaviti mogućnost PET/CT u procjeni metastatske aktivnosti uz pomoć parametara kao što je SUVmax uz komparaciju sa CT i scintigrafskim pregledima. 
Materijal i metode istraživanja

Istraživanje je sprovedeno kao retrospektivna deskriptivna studija u toku 2019. godine na Klinici za radiologiju i Klinici za nuklearnu medicinu i endokrinologiju Univerzitetskog kliničkog centra u Sarajevu. U istraživanje je uključeno 100 pacijentica starosne strukture 3379 godina. $\mathrm{Za}$ istraživanje su su se koristili podaci iz PACS-a (Pictures Archiving and Communications System) i RIS-a (Radiological Information System). U istraživanje je uključeno 100 pacijentica. Kriteriji za uključivanje ispitanika u studiju su bili dostupni PET/CT nalazi cijelog tijela sa pripadajućim snimcima drugih dijagnostičkih disciplina kao što je kompjuterizirana tomografija $\mathrm{i} /$ ili scintigrafija kostiju, do dvije godine starosti od datuma provođenja PET/CT procedure. Pored ovoga za istraživanje su se koristili podaci pacijentica koje su imale uputnu dijagnozu karcinoma dojke, sa suspekcijom na metastatsku aktivnost.

PET/CT pregled je rađen na GE Discovery 600 series aparatu, koristeći low dose whole body studiju. Snimanje se vršilo tačno 60 minuta nakon aplikacije radiofarmaka. Pacijent je pozicioniran na stolu u ležećem položaju, na leđima, sa rukama iznad glave, te je pomoću laserskih svjetala osigurano da su vrh glave i srednja aksilarna linija u centru uređaja.

Primarni fokus za komparaciju PET/CT snimaka sa snimcima drugih dijagnostičkih modaliteta, te sa kontrolnim PET/CT snimcima je na standardiziranim vrijednostima nakupljanja. Sve vrijednosti iznad 2,5 su smatrane metabolički aktivnim, od kojih su velika većina malignog karaktera, te su SUVmax vrijednosti maligne etiologije direktno poređene sa SUVmax upalne ili neke druge etiologije. Pomoću podataka SUVmax vrijednosti definiran je broj malignih lezija i direktno upoređen sa brojem lezija dijagnosticiranih metodama CT toraksa i abdomena, te scintigrafije kostiju, za šta su korišteni prikladni statistički testovi i statistički parametri. Uočena je i pribilježena lokalizacija metastatski aktivnih žarišta, kao i njihova strana u tijelu koja je poređena sa stranom primarnog tumora.

Statistička analiza podrazumijevala je deskriptivnu statistiku uz korištenje MannWhitneyevog testa za poređenje rezultata
PET/CT i konvencionalnih dijagnostičkih metoda, student t-testa za poređenje metastatski aktivnih SUV vrijednosti sa SUV vrijednostima druge etiologije, te statističke parametre senzitivnosti, specifičnosti $\mathrm{i}$ tačnosti u poređenju PET/CT procedure pojedinačno sa scintigrafskom kod evaluacije lezija kostiju, te CT-a kod evaluacije lezija na plućima i jetri.

\section{Rezultati}

Dob ispitanica je normalne razdiobe prema Kolmogorov-Smirnovljevom testu, sa vrijednostima $\mathrm{Z}=0,0834$ i $\mathrm{p}=0,463$ respektivno. Prosječna starost ispitanica iznosti 59,1 godinu, a prema starosnim skupinama najzastupljenije su ispitanice srednje životne dobi u udjelu 54 ispitanice (54\%). Najmlada ispitanica ima 33, a najstarija 79 godina.

Prosječna aplicirana doza ispitanici u studiji iznosi 349,83 MBq radiofarmaka 18-FDG. Najmanja doza iznosi 306,6, a najveća 399,6 MBq. Vrijednosti apliciranih doza su normalne razdiobe prema Kolmogorov - Smirnovljevom testu, gdje je $Z=0,074$ i p = 0,616.

Od 100 ispitanica koje su radile PET/CT proceduru, sa prethodno utvrđenom suspekcijom na metastatsku aktivnost, za njih 77 je ishod nalaza bio pozitivan na metastatsku aktivnost. Posmatrajući stranu primarnog tumora, te stranu tijela gdje su dijagnosticirane metastatski aktivne lezije, može se uočiti da kod 57 ispitanica, strana primarnog tumora korelira sa stranom udaljenih metastaza u organizmu, što se posmatra kroz procentualni udio od 74,03\%.

Posmatrajući SUVmax vrijednosti kod aktivnih žarišta za koje se sumnja da su malignog, a ne inflamatornog porijekla, uočavaju se 182 vrijednosti, za koje je prosječna aritmetička sredina 8,28. Najmanja vrijednost SUVmax iznosi 2,6, dok najveća vrijednost iznosi 28,2. Uptake metastatski aktivnih žarišta je signifikantno veći nego uptake kod uočenih žarišta inflamatorne ili druge etiologije, sa $\mathrm{p}$ vrijednosti student t-testa koja iznosi $\mathrm{p}<0,0001$ (dokazan nivo statističke značajnosti $\mathrm{p}<0,05$ ).

Od 77 posmatranih ispitanika sa dijagnosticiranim udaljenim metastazama, najčešća lokalizacija je ona u koštanom sistemu sa 44 zabilježena slučaja $(41,36 \%)$, a prate je 
metastaze u plućima sa 26 slučajeva, jetra sa 22 , te mozak u 1 slučaju.

Pri poređenju procjene metastatski aktivnih žarišta između PET/CT i drugih dijagnostičkih metoda, kao što su CT i scintigrafija skeleta, PET/CT nalaz je pozitivan na metastaze kod 77 ispitanika (77\%), dok je kod drugih dijagnostičkih metoda nalaz na metastaze pozitivan kod 56 ispitanika (56\%). Procjena metastatske aktivnosti karcinoma dojke sa PET/CT aparatom je signifikantno uspješnija u odnosu na navedene dijagnostičke discipline CT i scintigrafije kostiju, sa p vrijednosti MannWhitneyevog testa od $\mathrm{p}=0,010146$ (dokazan nivo statističke značajnosti $\mathrm{p}<0,05), \mathrm{u}$ vrijednosti od $\mathrm{U}=3950$ te $Z$ skorom $Z=-2,564$.

Senzitivnost CT dijagnostike iznosi $77,78 \%$, komparativno sa senzitivnosti PET/CT koja iznosi 92,59\%. Specifičnost CT i PET/CT dijagnostike iznosi $90,24 \%$ te $85,37 \%$ respektivno. Senzitivnost scintigrafije kostiju iznosi $77,42 \%$, komparativno sa senzitivnosti PET/CT koja iznosi 93,55\%. Specifičnost scintigrafije kostiju i PET/CT dijagnostike iznosi $100 \%$ i $88,89 \%$ respektivno.

\section{Diskusija}

Od ukupno 100 urađenih PET/CT procedura, detektirano je 77 udaljenih metastaza, od čega je po lokalizaciji najčešća metastaza kosti kod 44 ispitanika $(41,36 \%)$, pluća kod $26(24,4 \%)$, jetra kod $22(20,68 \%)$, te mozak kod 1 ispitanika $(1,88 \%)$. PET/CT ima svoju ulogu u detekciji udaljenih metastaza. Iako je superiorniji na polju senzitivnosti, specifičnosti i tačnosti u odnosu na konvencionalne dijagnostičke modalitete, ne spada u dio rutinskih pretraga (9). To se dijelom može pripisati i financijskim razlozima i skupoći procedure. U studiji Aliyeva i saradnika iz 2016. godine posmatrana je uloga PET/CT procedure $\mathrm{u}$ detekciji udaljenih metastaza, ali u svrhu inicijalnog stejdžinga, gdje se došlo do zanimljivih rezultata. Istraživanje je rađeno na 254 pacijenta, od kojih je kod njih 76 uočeno prisustvo udaljenih metastaza. $21,7 \%$ pacijenata je imalo udaljene metastaze u kostima, kod $17,1 \%$ su detektovane plućne metastaze, kod $14,8 \%$ metastaze na jetri. U konačnici, studija je dovela do promjene stejdžinga oboljenja, te promjene tretmanskog pristupa i samim tim pokazala superiornost u detekciji udaljenih metastaza (10).

Već je napomenuto da je kod 77/100 ispitanika uz pomoć PET/CT procedure uočena metastatska aktivnost, dok su druge konvencionalne i digitalne imidžing metode kao što su CT i scintigrafija kostiju otkrile kod 56/100 ispitanika metastatsku aktivnost. U poređenju sa istraživanjem koje je rađeno 2013. godine od Groheuxa i saradnika, gdje je uzorak bio 117 ispitanika, tu su otkrivene 43 udaljene metastaze uz pomoć PET/CT procedure, dok su drugi imidžing modaliteti, gdje su pored navedenih uključeni RTG te ultrazvuk, otkrili udaljene metastaze kod 28 ispitanika (11).

Senzitivnost CT dijagnostike iznosi 77,78\%, komparativno sa senzitivnosti PET/CT koja iznosi 92,59\%. Specifičnost CT i PET/CT dijagnostike iznosi $90,24 \%$ te $85,37 \%$ respektivno. Rezultati statističkih parametara senzitivnosti i tačnosti ukazuju na to da PET/CT pokazuje statistički signifikantno bolju senzitivnost, te ujednačenu specifičnost u odnosu na CT. Prema sprovedenoj meta-analizi, senzitivnost i specifičnost PET/CT za detekciju udaljenih metastaza iznosi $96 \%$ i 95\% respektivno (12). Među studijama koje su poredile PET/CT sa konvencionalnim imidžing modalitetima, ti parametri su išli u korist PET/CT sa senzitivnošću 97\% i specifičnošću $95 \%$ u odnosu na 56\% i 91\% kod konvencionalnih modaliteta (13). Za velike i potencijalno operabilne karcinome, PET/CT posjeduje $100 \%$ senzitivnost i $98 \%$ specifičnost za detekciju udaljenih metastaza, dok su ti omjeri $60 \%$ i $83 \%$ za konvencionalne metode (14). Prema istraživanju autora Almuhaideba i saradnika, PET/CT je pokazao senzitivnost, specifičnost i tačnost u procentima 100, 97 i 98, respektivno, u procjeni udaljenih metastaza (15).

Senzitivnost scintigrafije kostiju iznosi $77,42 \%$, komparativno sa senzitivnosti PET/CT koja iznosi 93,55\%. Specifičnost scintigrafije kostiju i PET/CT dijagnostike iznosi $100 \%$ i $88,89 \%$ respektivno. Rezultati pokazuju signifikantno veće vrijednosti senzitivnosti u korist PET/CTa, te specifičnosti u korist scintigrafije kostiju. Komparativno sa scintigrafijom kostiju PET/CT je pokazao bolje rezultate kod detekcije koštanih metastaza u meta-analizi provedenoj 2013. 
godine od strane Ronga i saradnika (16). PET/CT ima senzitivnost i specifičnost 93\% i $99 \%$ komparativno sa $81 \%$ i $96 \%$ scintigrafije kostiju. Zahvaljujući visokim vrijednostima specifičnosti i senzitivnosti, PET/CT posjeduje potencijal da postane rutinska pretraga kod pacijenata sa visokorizičnim karcinomom dojke, gdje je mogućnost razvijanja metastaze kostiju $30 \%(17)$.

\section{Zaključak}

Shodno dobijenim rezultatima istraživanja, kao i promatranim istraživanjima drugih autora, PET/CT je signifikantno uspješnija metoda u procjeni metastatske aktivnosti u odnosu na druge dijagnostičke discipline. Značajnije nakupljanje radiofarmaka FDG-18 je uočeno kod lezija metastatskog porijekla, u odnosu na lezije druge etiologije putem komparacije SUVmax vrijednosti. Najčešća lokalizacija metastaze je bila u skeletnom sistemu sa 41,6\% udjela, praćena metastatskom aktivnošću u plućima, jetri te mozgu. U direktnom poređenju sa CT dijagnostikom pluća i jetre i scintigrafijom skeleta, PET/CT je pokazao signifikatno veću senzitivnost, te podjednaku specifičnost.

\section{Reference}

1. Boellaard R, Delgado-Bolton R, Oyen WJ, Giammarile F, Tatsch K, Eschner $\mathrm{W}$ et al. FDG PET/CT: EANM procedure guidelines for tumour imaging: version 2.0. Eur J Nucl Med Mol Imaging. 2015;42(2):328-354.

2. Bockisch A, Freudenberg LS, Schmidt D, Kuwert T. Hybrid imaging by SPECT/CT and PET/CT: proven outcomes in cancer imaging. Seminars in nuclear medicine. 2009;39(4):276289.

3. Townsend D. Combined PET/CT: The Historical Perspective. Semin Ultrasound CT MR. 2008 August ; 29(4): 232-235.

4. Aroztegui APC, Vicente AMG, Ruiz AS , Bolton RCD, Rincon JO, Garzon JRG et al. 18F-FDG PET/CT in breast cancer:

Evidence-based recommendations in initial staging. Tumor Biology. 2017: 1-23.

5. Senkus E, Kyriakides S, Ohno S, Penault-Llorca F, Poortmans P, Rutgers
E, Zackrisson S et al. Primary breast cancer: ESMO Clinical Practice Guidelines for diagnosis, treatment and follow-up. Ann Oncol 2015; 26(Suppl. 5): 8-30.

6. Dodik D, Kusić Z. Klinička nuklearna medicina. Medicinska naklada Zagreb. 2012; 258-259.

7. Tatsumi M, Cohade C, Mourtzikos KA, Fishman EK, Wahl RL. Initial experience with FDG-PET/CT in the evaluation of breast cancer. Eur J Nucl Med Mol Imaging 2006;33:254-262.

8. Lind P, Igerc I, Beyer T, Reinprecht P, Hausegger K. Advantages and limitations of FDG PET in the followup of breast cancer. J Nucl Med 2009; 22: 387-397.

9. Riegger C, Herrmann J, Nagarajah J, Hecktor J, Kuemmel S, Otterbach F et al. Whole-body FDG PET/CT is more accurate than conventional imaging for staging primary breast cancer patients. Eur J Nucl Med Mol Imaging 2012; 39: 852-63.

10. Aliyev A, Yilmaz S, Ozhan M, Ekmekcioglu O, Vatankulu B, Kocael PC et al. The role of FDG PET/CT in detection of distant metastasis in the initial staging of breast cancer. Turkish Journal of Medical Sciences. 2016; 46: 349-360.

11. Groheux D, Giachetti S, Delord M, Hindie E, Vercellino L et al. 18F-FDG $\mathrm{PET} / \mathrm{CT}$ in staging patients with locally advanced or inflammatory breast cancer: comparison to conventional staging. J Nucl Med 2013; 54: 5-11.

12. Jodlowska E, Czepczynski R, Wyszomirska A, Jarzabek G, Kedzia W, Rchala M. Application of positron emission tomography (PET/CT) in diagnosis of breast cancer.Contemp Oncol. Poznan. 2016; 20 (1): 8-12.

13. Hong S, Li J, Wang S. 18FDG PET-CT for diagnosis of distant metastases in breast cancer patients. A meta-analysis. Surg Oncol 2013; 22: 139-43.

14. Fuster D, Duch J, Paredes P, Velasco M, Muñoz M, Santamaría G, Fontanillas M, Pons F. Preoperative staging of large primary breast cancer with 
[18F]fluorodeoxyglucose positron emission tomography/computed tomography compared with conventional imaging procedure. J Clin Oncol 2008; 26: 4746-51.

15. Almuhaideb A, Papathanasiou $\mathrm{N}$, Bomanji J. 18F-FDG PET/CT Imaging in Oncology. Ann Saudi Med 2011; 31(1):3-13.

16. Rong J, Wang S, Ding Q, Yun M, Zheng Z, Ye S. Comparison of 18FDG PET-
CT and bone scintigraphy for detection of bone metastases in breast cancer patients. A meta-analysis. Surg Oncol 2013; 22: 86-91.

17. Aukema TS, Straver ME, Peeters MJ, Russell NS, Gilhuijs KG, Vogel WV et al. Detection of extra-axillary lymph node involvement with FDG PET/CT in patients with stage II-III breast cancer. Eur J Cancer 2010; 46: 3205-10. 